\title{
Genetic polymorphism of the mannose-binding protein gene in children with sickle cell disease: identification of three new variant alleles and relationship to infections
}

\author{
Maria-Grazia Neonato ${ }^{1,2}$, Chang Yong Lu ${ }^{1,4}$, Monique Guilloud-Bataille ${ }^{3}$, \\ ${ }^{1}$ INSERM U458, Hôpital Robert Debré \\ ${ }^{2}$ Laboratoire d'Hématologie and FAMBA de Biologie Moléculaire, Hôpital Tenon \\ ${ }^{3}$ INSERM U155, Paris, France \\ ${ }^{4}$ CIRMF, Franceville, Gabon
} Claudine Lapouméroulie ${ }^{1}$, Hassan Nabeel-Jassim ${ }^{1}$, Dominique Dabit ${ }^{2}$, Robert Girot ${ }^{1,2}$, Rajagopal Krishnamoorthy ${ }^{1}$, Josué Feingold ${ }^{3}$, Claude Besmond ${ }^{1}$ and Jacques Elion ${ }^{1}$

\begin{abstract}
Mannose-binding protein (MBP) is a serum lectin that participates in the innate immune response. MBP deficiency may constitute a risk factor in the development of infections. Three MBP structural variants have been identified with a dominant effect on MBP serum concentration. Similarly, polymorphisms in the promoter of the corresponding gene $(H S M B P 1 B)$ have been related to variations of MBP concentration in serum. Children with sickle cell disease (SCD) have an increased susceptibility to infections with encapsulated organisms resulting in meningitis, septicaemia, and osteomyelitis. We have investigated the HSMBP1B genotype in 242 children with SCD living in Paris. Apart from the known variant alleles, we identified three novel ones and report their distribution in our sample population. In addition, we found rather unexpectedly an increased frequency of the variant alleles in patients who had not suffered severe infections.
\end{abstract}

Keywords: sickle cell disease; mannose-binding protein; polymorphism; infection

\section{Introduction}

Haemoglobin $\mathrm{S}(\mathrm{HbS})$ is the result of a single mutation in the $\beta$-globin gene, but sickle cell disease (SCD) is the result of many genes. The extreme variability in the

Correspondence: Jacques Elion, INSERM U458, Hôpital Robert Debré, 48, boulevard Sérurier, F-75019 Paris, France. Tel: + 331400323 39; Fax: + 331400322 77; E-mail: jacques.elion@rdb.ap-hop-paris.fr

Received 11 January 1999; revised 16 April 1999; accepted 28 April 1999 severity of the disease has always been a puzzle for clinicians. ${ }^{1,2}$ Genetically-determined alleviating factors have been identified, such as the coinheritance of $\alpha$-thalassaemia ${ }^{3}$ and the persistence of high levels of foetal haemoglobin $(\mathrm{HbF}){ }^{4}$ Genetic determinants involved in high $\mathrm{HbF}$ production are either linked to the $\beta$-globin gene locus on chromosome 11,5 or unrelated, such as the X-linked FCP locus ${ }^{6}$ and a locus on chromosome 6. ${ }^{7}$ Thus various genes in the patient's genetic background contribute to the phenotypic variation of the disease. 
Children with SCD have an increased susceptibility to infection with encapsulated organisms despite penicillin prophylaxis and/or vaccination. Meningitis, septicaemia, and osteomyelitis are a significant cause of morbidity and mortality. ${ }^{1,2}$ Genetic influence on susceptibility to infections is an exciting emerging field of investigation. ${ }^{8}$ Here we investigated the potential relationship between polymorphism in the mannose-binding protein $(M B P)$ gene and infectious episodes in SCD children.

MBP is a serum lectin that participates in the nonspecific innate immune defence. It is encoded by the HSMBP1B gene on chromosome $10 .{ }^{9,10}$ Three point mutations in exon 1 of this gene have been identified which result in the production of structural MBP variants (G57E, G54D and R52C). ${ }^{11-13}$ Production of these variants exerts a dominant effect on MBP serum concentration. Polymorphisms in the $H S M B P 1 B$ promoter have also been described which define four haplotypes (HY, HX, LY, LX), and these haplotypes have been related to various levels of $H S M B P 1 B$ expression. ${ }^{14}$ Thus, deficient genotypes at the HSMBP locus fall into two classes. First, heterozygote and homozygote genotypes including the classical structural variants are associated with a serum MBP level lower than $500 \mu \mathrm{g} / \mathrm{ml}$. Second, similarly low serum MBP levels are observed in homozygotes for the LX haplotype in the promoter. Individuals with other haplotype combinations exhibit mean serum MBP levels varying from 1000 to $2300 \mu \mathrm{g} / \mathrm{ml}^{14}$ Low serum MBP has been associated with an increased susceptibility to recurrent infections. ${ }^{15-18}$ Indeed, it may constitute a particular transient risk factor early in infancy because of the maturational lag in the infant's antibody system.

Here we report the distribution of the known variant alleles at the HSMBP1 locus in 242 SCD children living in Paris and we describe three novel variant alleles. Rather unexpectedly, we find an increased frequency of the variant alleles in SCD children who had not suffered from severe infections.

\section{Material and Methods}

\section{Patients}

After the informed consent of the parents had been obtained, 242 children with SCD were included in the study. Ages ranged from 36 months to 18 years (mean age 10.1 \pm 5.8 ); $55 \%$ were male $(n=133)$ and $45 \%$ female $(n=109)$. Origin of the parents was documented in most of the cases and was as follows: Western Africa (71 children, 29.3\%), North Equatorial Central Africa (46 children, 19.0\%), South Equatorial Central Africa (50 children, 20.6\%), and French West Indies
(64 children, $26.4 \%$ ); $76 \%$ of the children were born in France. Diagnosis of SCD and haemoglobin genotypes were established by standard procedures and family studies. ${ }^{6}$ Two hundred and fifteen patients were SS homozygotes and 27 were SC compound heterozyotes. All patients were regularly attending four participating specialised centres in Paris (Hôpital Robert Debré, Hôpital Necker-Enfants Malades, Hôpital Tenon, and Hôpital Armand Trousseau). Medical records were available for at least the past 3 years. Biological data included regular haematology follow-ups, HbF levels, $\beta$-globin gene haplotypes, and $\alpha$-globin gene status. All the patients under 10 were treated with oral penicillin and immunised against Streptococcus pneumoniae and Haemophilus influenzae type b.

\section{Genotyping by Denaturing Gradient Gel Electrophoresis (DGGE) and PCR Restriction Fragment Length Polymorphism (PCR-RFLP)}

$H S M B P 1 B$ exon 1 was amplified by the polymerase chain reaction (PCR). PCR products were first screened for sequence variations by means of DGGE. ${ }^{19}$ Abnormal profiles were then analysed by PCR-RFLP and when necessary by DNA sequencing. To test for the known G54D and G57E mutations, PCR products were digested with BanI and MboII (New England Biolabs, Beverly, MA, USA), respectively. ${ }^{20}$ The newly described variants were tested as follows. The IVSI-5 $(\mathrm{G} \rightarrow \mathrm{A})$ transition produces an NlaIII restriction site, whereas the other two novel S39N and S40A mutations abolish an AluI site and create a MaeIII and a HaeII site, respectively. PCR products were thus digested with these enzymes (New England Biolabs). In all cases, digestion fragments were separated by electrophoresis through a nondenaturing $6 \%$ polyacrylamide gel. Gels were examined under UV transillumination after staining with ethidium bromide $(0.5 \mu \mathrm{g} / \mathrm{ml})$ for $15 \mathrm{~min}$.

\section{Promoter Genotyping by Allele Specific PCR}

Allele-specific PCR was used to determine the $H S M B P 1$ promoter haplotype. The primers were those described by Sullivan $e t a l^{11}$ and the annealing temperature was $63.5^{\circ} \mathrm{C}$. The four combinations of the two forward and the two reverse primers allow the identification of the four LY, LX, HY, and HX haplotypes.

\section{DNA Sequencing}

PCR products were sequenced by the dideoxynucleotide method using the Drhodamine Terminator Cycle Sequencing Kit (Perkin Elmer, Foster City, USA). Sequence reactions were resolved on an ABI PRISM 373 automatic sequencer (Perkin Elmer).

\section{Statistical Analysis}

Phenotypic or allelic differences between groups were evaluated by $\chi^{2}$ test.

\section{Results}

\section{Distribution of MBP Variant Alleles in the Studied Population}

$H S M B P 1$ exon 1 and its flanking sequences have been analysed by PCR and DGGE in the 242 SCD children. 
Eleven abnormal patterns were observed (Figure 1) and the corresponding PCR fragments were sequenced. Five patterns corresponded to different combinations between the normal allele and the three variant alleles previously described R52C $(\mathrm{C} \rightarrow \mathrm{T})$; G54D $(\mathrm{G} \rightarrow \mathrm{A})$ and G57E $(\mathrm{G} \rightarrow \mathrm{A})$ (Figure 2). The two single-nucleotide polymorphisms at positions -550 and -221 in the HSMBP1 promoter which define the LY, LX, HY, and HX haplotypes (Figure 2) were studied by allelespecific PCR (results not shown). Analysis of linkage between the structural variant and the promoter haplotype indicates that G57E is found mostly on LY chromosomes (LY-G57E $=97 \%$ ), but also on HY and LX chromosomes (HY-G57E $=2 \%$ and LX-G57E $=1 \%$ ). G54D was found exclusively on LY chromosomes (LY-G54D), and the single R52C chromosome in our series was LX (LX-R52C). Allele frequencies in the total population studied are shown in Table 1. The population was also divided into five groups according to their geographic origin: Western Africa, North Equatorial Central Africa, South Equatorial Africa, French West Indies, and unknown/mixed origin. The major G57E structural allele seems to be more prevalent in Western than in Central Africa. On the other hand, the LX promoter haplotype which has been linked to low serum MBP may be more prevalent in Central Africa.

\section{Description of Three Novel MBP Variant Alleles}

The other six variations in the DGGE patterns corresponded to genotypic combinations involving three novel variant alleles. One is a $\mathrm{G} \rightarrow \mathrm{A}$ transition at position 5 in the first intron (IVS-I-5) and two are located in the coding sequence. The first is a $\mathrm{G} \rightarrow \mathrm{A}$ transition at nt 2 of codon 39 and the second a $\mathrm{T} \rightarrow \mathrm{G}$ transition at nt 1 of codon 40 ; both are missense mutations that correspond to Serine $\rightarrow$ Asparagine $(\mathrm{S} 39 \mathrm{~N})$ and to Serine $\rightarrow$ Alanine (S40A) replacements, respectively, at the protein level (Figure 2). The IVS-I-5 mutation creates a NlaIII site, whereas the $\mathrm{S} 39 \mathrm{~N}$ and S40A mutations abolish an AluI site and create a MaeIII site and a HaeII site, respectively. This was used to confirm the data from the sequence analysis by PCRRFLP (results not shown). Frequencies of these novel alleles in the studied population are shown in Table 1. The IVS-I-5 and S39N variations were found on LY chromosomes (LY-IVS-I-5 and LY-S39N) and the S40A allele on an LX chromosome (LX-S40A). At present the phenotypic consequences of these new alleles are not known.

\section{MBP Variant Alleles and Infections}

Distribution of the various MBP genotypes in our population of SCD patients is shown in Table 2. There was a single LX/LX homozygote whose actual genotype was LX-wild/LX-G57E. Altogether, genotypes classically associated with low serum MBP are found in $52 \%$ of the patients.

To study the relationship between the MBP variant alleles and infections, only the children with homozygous SCD (SS patients) were considered in order to avoid potential bias from different globin genotypes. In this series of $215 \mathrm{SS}$ children, frequencies of the various

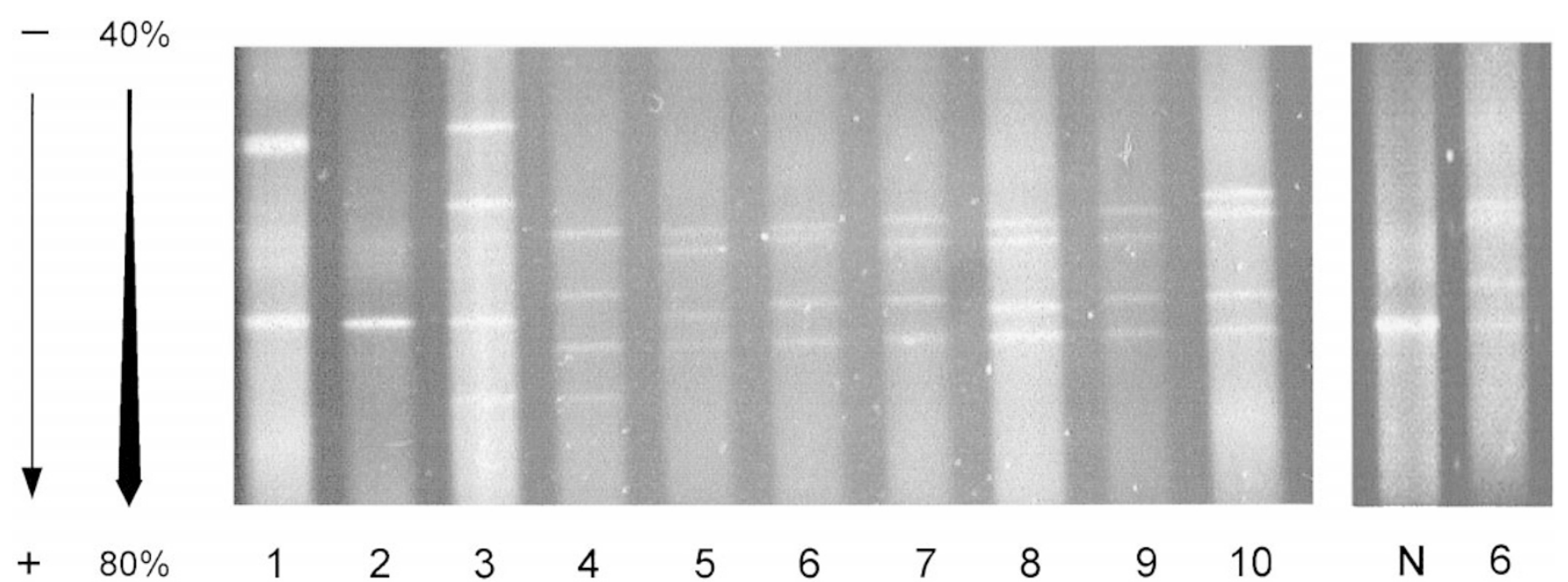

Figure 1 DGGE analysis of PCR-amplified HSMBP1B exon 1. Altogether 11 different profiles were observed in this study of which 10 are shown here. Corresponding genotypes are as follows: Lane $1=$ G57E/IVS-I-5; Lane $2=$ G57E/G57E; Lane $3=$ G57E/S40A; Lane $4=w / S 40 A ;$ Lane $5=w / G 57 E ;$ Lane $6=w / G 54 D ;$ Lane $7=w / R 52 C ;$ Lane $8=$ Lane $; ;$ Lane $9=w / I V S-I-5 ;$ Lane $10=w /$ S39N; Lane $N=w / w$ 
MBP variant alleles were not significantly different from those shown in Table 1 for the overall population of 242 SCD patients. However, the single carrier for the LX-R52C allele was no longer included as he was an SC compound heterozygote. Similarly, the frequency of genotypes associated with low serum MBP was not different in this subset of patients (50vs 52\%). Mean age of the children in the group with low serum MBP genotypes was not different from that of the group with the other genotypes $(10.2 \pm 6.0 v s 10.0 \pm 6.0)$. Fortythree children $(20 \%)$ had a history of severe infections defined as meningitis, septicaemia, or osteomyelitis. At

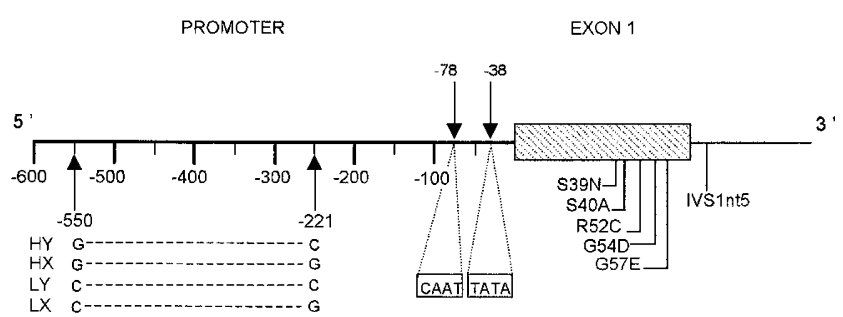

Figure 2 Schematic representation of the HSMBP1B 5' region. The location of the two single nucleotide polymorphisms in the promoter is shown, as well as that of the various structural variants in exon 1 and of the IVS1 variant described in this study. Specific linkage of the promoter polymorphisms that define the four $H Y, H X, L Y$, and $L X$ haplotypes are given, independently from the sequence variations in exon 1. the time of the study, the age distribution of the two groups of children was not different. However, the risk of infection was related to age, as infectious events had occurred before the age of 5 years in $65 \%$ of the cases (28/43).

When frequencies of the various MBP alleles are compared between the two groups of children with $(n=43)$ and without $(n=172)$ infection, an almost two-fold enrichment of the G57E and G54D alleles is observed in the latter group (31.1\% vs $16.7 \%$, $P=0.01)$. Frequency of the LX-wild allele did not differ in the two groups, nor did the frequency of the newly described alleles of uncertain pathophysiological consequences.

When the comparison between infected $v s$ non infected children is made at the genotype level, similar results are obtained (Table 3 ). When all the MBP variant alleles observed in the study are taken into account, the respective frequencies of abnormal genotypes are $34.9 \%$ in the infected children $v s 55.2 \%$ in the children with no infections $(P=0.02)$ (Table 3 , column 2). When the carriers of the IVS-I-5, S39N, and S40A alleles are left out of the comparison because of their uncertain functional significance, the respective frequencies of deficient genotypes become $31.7 \%$ vs $53.0 \%(P=0.01)$ (Table 3, column 3$)$. Finally, the same level of significance in the difference between

Table 1 Frequency of the HSMBP1B alleles in the studied population of 242 SCD children. Children have been split into groups according to their geographic origin: $27 \%$ of the children were from Atlantic West Africa, $19 \%$ from North Equatorial Central Africa, 21\% from South Equatorial Central Africa, 26\% from the French West Indies, and 6\% of unknown origin

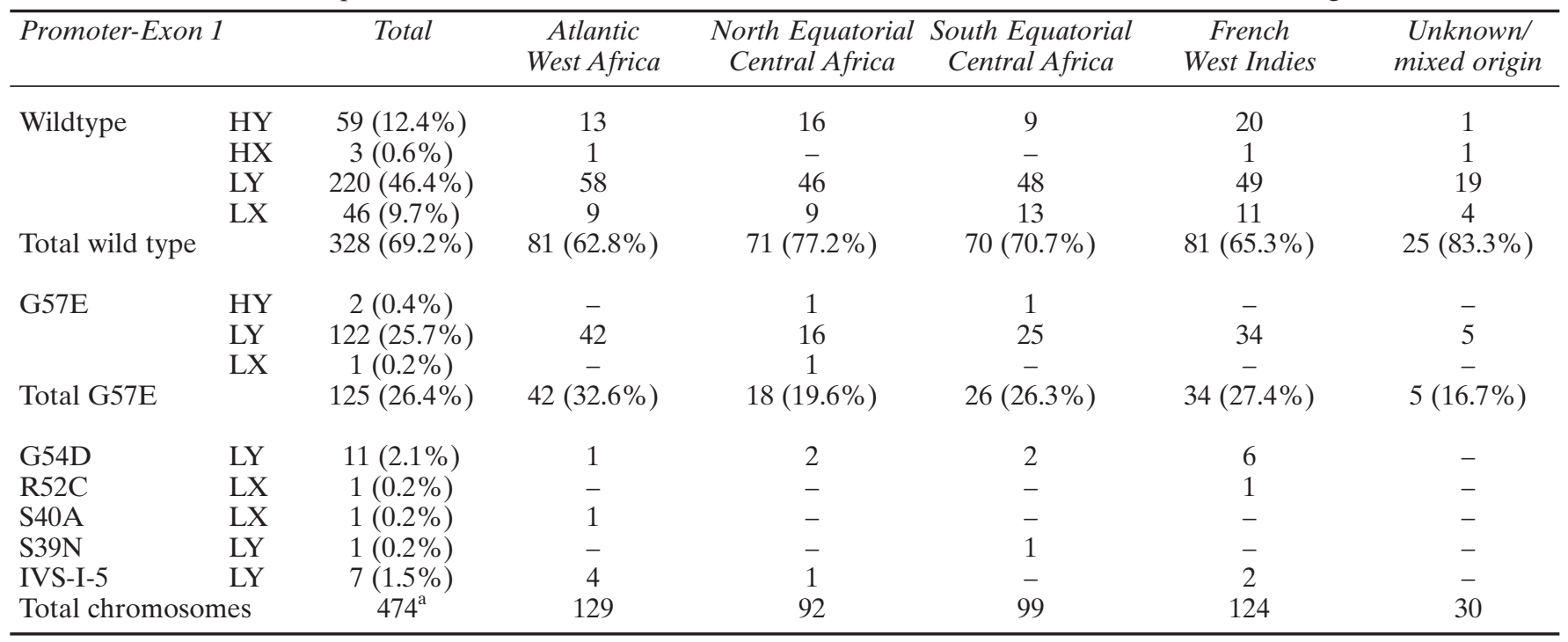

${ }^{\mathrm{a}}$ For 5 of 242 patients the promoter haplotype could not be determined: 4 were w/w homozygotes and 1 was $40 / \mathrm{w}$ heterozygote. Atlantic West Africa = Guinea, Mali, Mauritania, Senegal. North Equatorial Central Africa = Benin, Cameroon, Ivory Coast, Niger, Togo. South Equatorial Central Africa = Congo, Gabon, PCR, Zaire. 
Table 2 Distribution of the HSMBP1B genotypes in the studied population. Of the patients studied 52\% had genotypes known to be linked to a low MBP production (in bold).

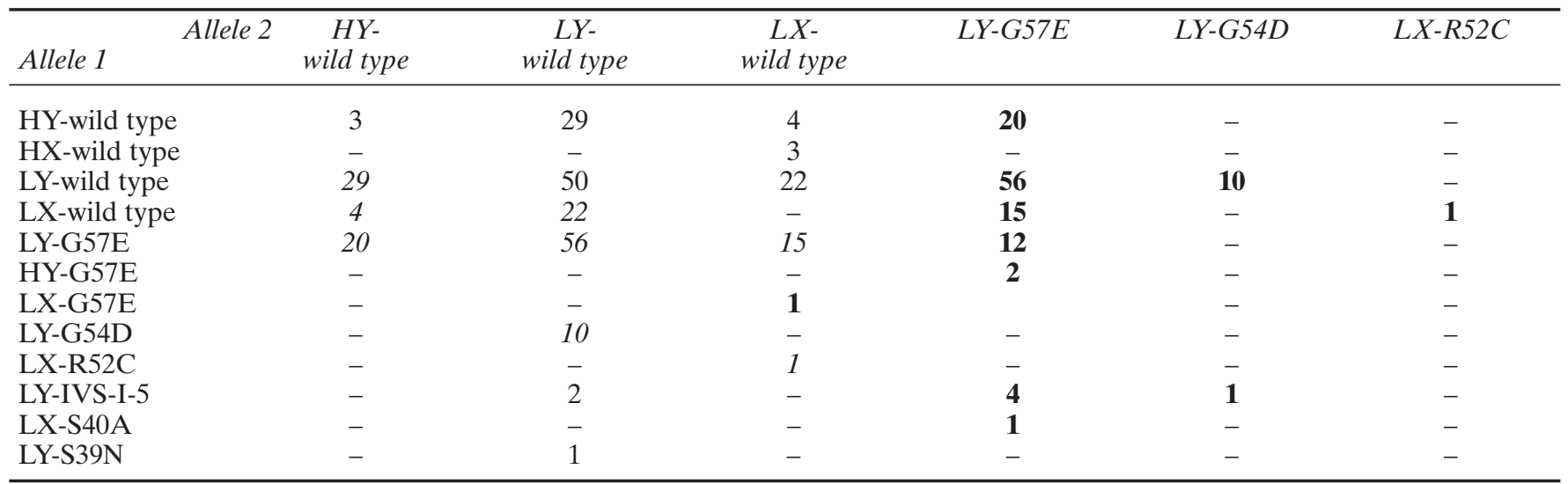

Allele 1 reads vertically and allele 2 horizontally. The number of individuals for a given two-allele combination (genotype) appears at the intersection of a line and column. Since a given genotype may be found at two intersections, the number of patients with this genotype may appear twice. In such cases, the number of patients is in italics at the second intersection.

the two groups $(P=0.02)$ is observed when all the subjects are taken into account and the newly described alleles are considered neutral (Table 3, column 4).

\section{Discussion}

We have analysed the distribution of $H S M B P 1 B$ variant alleles in a series of 242 SCD children living in France. Except for those originating from the French West Indies, the genetic background of the children is fairly homogeneous and representative of their ethnic origin in Africa. ${ }^{6}$ Indeed, most are children of unmixed first generation immigrants to France. This is best illustrated by the fact that $67 \%$ of these children are homozygotes for a given $\beta^{\text {s}}$-globin haplotype even though the relative allelic representation of the Benin, Bantu (CAR), and Senegal haplotypes among the overall population was $1: 1: 0.7$, ie a clear bias in a Hardy-Weinberg distribution (results not shown). This is in contrast to the distribution of the $\beta^{\mathrm{s}}$-globin haplotype observed in our patients from the West Indies and in a series from Jamaica ${ }^{1,22}$ or North America ${ }^{23}$ which clearly indicates the genetic admixture of these populations. Thus our data can be reasonably interpreted in epidemiological terms concerning the distribution of MBP variants in African populations. They confirm to a great extent previous studies $^{24}$ in showing an overall frequency of the structural variants of roughly $31 \%$ in Africa, as compared with $20 \%$ in the Caucasian population. ${ }^{24}$ G57E, the most common variant in African populations (here $26.4 \%$ ), might be slightly more prevalent in Western Africa with a frequency of $32.6 \%$. Similarly, Bellamy et al found a frequency of $30.0 \%$ in a series of 2000 individuals in Gambia. ${ }^{25}$ In respect of the promoter

Table $3 H S M B P 1 B$ genotypes and infectious events in the subclass of 215 homozygous SS children

\begin{tabular}{|c|c|c|c|c|}
\hline MBP Genotype & $\begin{array}{c}\text { Normal } \\
I^{\mathrm{a}}\end{array}$ & $I I^{\mathrm{b}}$ & $\begin{array}{c}\text { Abnormal } \\
\text { III }^{\mathrm{c}}\end{array}$ & $I V^{\mathrm{d}}$ \\
\hline Promoter-exon 1 & $\mathrm{w} / \mathrm{w}$ & $\begin{array}{c}\mathrm{w} / \mathrm{V}^{+}, \mathrm{G} 57 \mathrm{E} / \mathrm{G} 57 \mathrm{E} \\
\text { and } \mathrm{V}^{+} / \mathrm{V}^{+\prime}\end{array}$ & $\begin{array}{c}\text { w/V and } \\
\text { G57E/G57E }\end{array}$ & $\begin{array}{c}\mathrm{w}^{+} / \mathrm{V} \\
\mathrm{G} 57 \mathrm{E} / \mathrm{G} 57 \mathrm{E}\end{array}$ \\
\hline No infection & $77(44.8 \%)$ & $\begin{array}{c}95(55.2 \%) \\
P=0.02\end{array}$ & $\begin{array}{c}87(53.0 \%) \\
P=0.01\end{array}$ & $\begin{array}{c}91(54.2 \%) \\
P=0.02\end{array}$ \\
\hline Infection & $28(65.1 \%)$ & $15(34.9 \%)$ & $13(31.7 \%)$ & $14(33.3 \%)$ \\
\hline
\end{tabular}

${ }^{\mathrm{a}} \mathrm{w} / \mathrm{w}$ is homozygous wildtype; there was no LX-w/LX-w in our series of patients

${ }^{\mathrm{b}} \mathrm{w} / \mathrm{V}^{+}$is heterozygosity for any of the variants found in our study (G57E, G54D, R52C, S40A, S39N, and IVS-I-5), $\mathrm{V}^{+} / \mathrm{V}^{+}$is compound heterozygosity for two different variants

${ }^{c} \mathrm{w} / \mathrm{V}$ is heterozygosity for G57E or G54D; carriers of the newly described variants have been left out from the comparison

${ }^{\mathrm{d}} \mathrm{w}^{+} / \mathrm{V}$ is heterozygosity for G57E or G54D; all the subjects have been included in the comparison; the newly described variant alleles are considered neutral, thus $\mathrm{w}^{+}$is wild-type (w) or any of the newly described alleles

$P=$ statistical significance 
haplotype, we find a $10 \%$ overall frequency of LX chromosomes. In comparison, Madsen et al reported a frequency of $24 \%$ in a series of 61 adults from Kenya. ${ }^{14}$ Our data show an increasing gradient in the LX haplotype frequency from West to Central Africa, thus this apparent discrepancy might reflect the extension of this gradient to East Africa. The frequency of the LX haplotype was $23 \%$ in a series of 120 Caucasoids. ${ }^{14}$

Here we describe three novel variant alleles at the $H S M B P 1 B$ locus. Two variants are structural alleles that result in amino acid substitutions at the protein level. However, unlike 'classic' structural variants, they do not lie in the collagenous domain of the molecule which is thought to be involved in its supramolecular assembly. Thus they might very well correspond to neutral proteic polymorphisms. The third mutation is in the IVS-I splicing donor site. Exactly the same mutation in the $\beta$-globin gene results in impaired splicing and $\beta^{+}$-thalassaemia. ${ }^{26}$ In addition, the IVS-I-5 mutation is linked to the LY configuration of the promoter which has been shown to indicate a slightly reduced MBP expression in comparison with the HY configuration. Thus the additional effects of these two polymorphisms on the same chromosome might well result in a deficient allele. Definitive demonstration of this potential effect will require mRNA and protein analysis.

Infectious diseases have been a major selective force in human evolution. ${ }^{27,28}$ Genetic susceptibility or resistance to various infections have greatly influenced the selection of several major genetic diseases. In African populations, the selective advantage of $\mathrm{HbS}$ carriers against the severe complications of Plasmodium falciparum infection has favoured the $\beta^{\mathrm{s}}$-gene. ${ }^{29}$ In Caucasian populations, resistance to cholera and other dehydrating intestinal diseases is thought to be the selective advantage that has favoured the emergence of mutations in the CFTR gene causing cystic fibrosis. ${ }^{30}$ Genetic variability to malaria also involves proteins of the immune system, including HLA antigens and a variety of cytokines or other molecules that regulate the response to infection. ${ }^{28,31}$ Ezekowitz identifies the genetic heterogeneity of MBP as the 'Jekyll and Hyde' of innate immunity. ${ }^{32}$ Indeed, on the one hand, several studies in children and adults indicate that the structural MBP variants predispose to severe infections, ${ }^{11,15-18}$ whereas on the other their high frequency in Africa suggests that low serum MBP cannot be exclusively disadvantageous, but that there is a positive selection in favour of low-producing variants. ${ }^{14}$ Selection mechanisms may work in 'wondrous ways'. For instance, selection of $\alpha$-thalassaemia genes by malaria has been shown to result from an increased susceptibility to uncomplicated infection with Plasmodium vivax early in life which, by hastening acquisition of immunity, leads subsequently to protection against lethal infections with $P$. falciparum. ${ }^{33,34}$ However, no selective advantage of the low MBP producing variants yet has been clearly demonstrated in African populations. In extensive studies of malaria, HBV persistence, and tuberculosis in Gambia, no evidence was found to link MBP variants either to resistance or susceptibility to infection. ${ }^{25}$ Similar results were reported in a study concerning HIV infection in Uganda (Ali S, Witworth J, Hill AVS, unpublished data, cited by $\mathrm{Hill}^{8}$ ) but increased susceptibility to infection and shorter survival time after infection was linked to low-producing variants in the Danish population. ${ }^{16}$

Only one previous report deals with genetic factors that could constitute an additional risk of infection in SCD. Because of its role in the clearance of encapsulated organisms, Norris et al studied the Fc receptor genotype in $60 \mathrm{SCD}$ children having suffered from infectious episodes. ${ }^{35}$ Whereas the $\mathrm{H} / \mathrm{H}^{131}$ genotype is under-represented in normal individuals with recurrent respiratory tract infections, it was over-represented in SCD children with infection, but only for children infected with $H$. influenzae. Here, we observed an association between low-producing MBP genotypes and the absence of infection in SCD children. None of the children in our series was infected with $H$. influenzae, the most prevalent organisms being $S$. pneumoniae, Salmonella sp, and S. aureus. SCD is influenced by many factors that might obscure this type of analysis. But our groups of patients (with/without infections and carriers/non carriers of MBP variants) were indistinguishable one from another in age, gender, total $\mathrm{Hb}$ and $\mathrm{HbF}$ levels, $\alpha$-globin gene number, $\beta^{\text {s}}$-gene haplotype, environment and health care. Thus, in contrast to the increased susceptibility to infection of MBP variant carriers reported in normal children, ${ }^{11,17,18}$ our results could suggest a protective role of MBP mutations in children with SCD. However, our SCD children (and most of Norris' children ${ }^{35}$ ) were given penicillin prophylaxis and immunisation against $S$. pneumoniae and $H$. influenzae. Thus circumstances are very different and results obtained for SCD children cannot be directly compared with those obtained for normal children. The possible role of superimposed genetic predisposition to infection in SCD is important to assess definitively, as knowledge of it might lead to 
very practical procedures to prevent one of the major complications of SCD.

\section{Acknowledgements}

This work was supported by institutional funding to the INSERM U458, and by grants CRC 96090 from the Assistance Publique-Hôpitaux de Paris and TS3*-CT93-0244 from the European Commission. The authors are indebted to Drs M de Montalembert, M Belloy, M Benkerrou, R Ducrocq, B Quinet, $\mathrm{P}$ Beauvais and $\mathrm{P}$ Begué for providing clinical and biological data.

\section{References}

1 Serjeant GR: Sickle cell disease. Oxford University Press: Oxford, 1992.

2 Embury SH, Hebbel RP, Mohandas N, Steinberg MH: Sickle cell disease: basic principles and clinical practice. Raven Press: New York, 1994.

3 Embury SH, Dozy AM, Miller J et al: Concurrent sicklecell anemia and alpha-thalassemia: effect on severity of anemia. N Engl J Med 1982; 306: 270-274.

4 Jackson JF, Odom JL, Bell WN: Amelioration of sickle cell disease by persistent fetal hemoglobin. J Am Med Ass 1961; 177: 867-869.

5 Labie D, Elion J: Sequence polymorphisms of potential functional relevance in the beta-globin gene locus. Hemoglobin 1996; 20: 85-101.

6 Chang YP, Maier-Redelsperger M, Smith KD et al: The relative importance of the X-linked FCP locus and betaglobin haplotypes in determining haemogloblin F levels: a study of SS patients homozygous for beta S haplotypes. $\mathrm{Br}$ J Haematol 1997; 96: 806-814.

7 Thein SL, Sampiero M, Rohde K et al: Detection of a major gene for heterocellular hereditary persistence of fetal hemoglobin, after accounting for genetic modifiers. Am J Hum Genet 1994; 54: 214-228.

8 Hill AV: The immunogenetics of human infectious diseases. Annu Rev Immunol 1998; 16: 593-617.

9 Sastry K, Herman GA, Day L et al: The human mannosebinding protein gene. Exon structure reveals its evolutionary relationship to a human pulmonary surfactant gene and localisation to chromosome 10. J Exp Med 1989; 170: 1175-1189.

10 Taylor ME, Brickell PM, Craig RK, Summerfield JA: Structure and evolutionary origin of the gene encoding a human serum mannose-binding protein. Biochem J 1989; 262: 763-771.

11 Sumiya M, Super M, Tabona P et al: Molecular basis of opsonic defect in immunodeficient children. Lancet 1991; 337: $1569-1570$.

12 Lipscombe RJ, Sumiya M, Hill AVS et al: High frequencies in African and non-African populations of independent mutations in the mannose binding protein gene. Hum Mol Genet 1992; 9: 709-715.

13 Madsen HO, Garred P, Kurtzhals JAL et al: A new frequent allele is the missing link in the structural polymorphism of the human mannan-binding protein. Immunogenetics 1994; 40: 37-44.
14 Madsen HO, Garred P, Thiel S et al: Interplay between promoter and structural gene variants control basal serum level of mannan-binding protein. J Immunol 1995; 155: 3013-3020.

15 Summerfield JA, Ryder S, Sumiya M et al: Mannose binding protein gene mutations associated with unusual and severe infections in adults. Lancet 1995; 345 886-889.

16 Garred P, Madsen HO, Balslev U et al: Susceptibility to HIV infection and progression of AIDS in relation to variant alleles of mannose-binding lectin. Lancet 1997; 349: 236-240.

17 Summerfield JA, Sumiya M, Levin M, Turner MW: Association of mutations in mannose binding protein gene with childhood infection in consecutive hospital series. $\mathrm{Br}$ Med J 1997; 314: 1229-1232.

18 Hibberd ML, Sumiya M, Summerfield JA, Booy R, Levin $\mathrm{M}$, and the Meningoccal Research Group: Association of variants of the gene for mannose-binding lectin with susceptibility to meningoccal disease. Lancet 1999; 353: 1049-1053.

19 Gabolde M, Krishnamoorthy R, Besmond C: Genotyping of the three structural allelic variants of the human mannose-binding lectin gene by means of denaturing gradient gel electrophoresis. Hum Mutat (in press).

20 Super M, Gillies SD, Foley S et al: Distinct and overlapping functions of allelic forms of human mannose binding protein. Nat Genet 1992; 2: 50-55.

21 Sullivan KE, Wooten C, Goldman D, Petri M: Mannosebinding protein genetic polymorphisms in black patients with systemic lupus erythematosus. Arthritis Rheum 1996; 39: 2046-2051.

22 Keclard L, Romana M, Lavocat E, Saint-Martin C, Berchel C, Merault G: Sickle cell disorder, beta-globin gene cluster haplotypes and alpha-thalassemia in neonates and adults from Guadeloupe. Am J Hematol 1997; 55: 24-27.

23 Steinberg $\mathrm{MH}, \mathrm{Hsu} \mathrm{H}$, Nagel RL et al: Gender and haplotype effects upon hematological manifestations of adult sickle cell anemia. Am J Hematol 1995; 48: $175-181$.

24 Lipscombe RJ, Beatty DW, Ganczakowski M et al: Mutations in the human mannose-binding protein gene: frequencies in several population groups. Eur J Hum Genet 1996; 4: 13-19.

25 Bellamy R, Ruwende C, Mcadam KPWJ et al: Mannose binding protein deficiency is not associated with malaria, hepatitis B carriage nor tuberculosis in Africans. $Q \mathrm{~J} \mathrm{Med}$ 1998; 91: 13-18.

26 Lapouméroulie C, Acuto S, Rouabhi F, Labie D, Krishnamoorthy R, Bank A: Expression of a beta thalassemia gene with abnormal splicing. Nucleic Acids Res 1987; 15: 8195-8204.

27 Haldane JB: The rate of mutation of human genes. Proc VIIIth Int Congr Genet Hereditas 1949; 35 (suppl): 267-272.

28 Weatherall DJ: The genetics of common disease: the implications of population variability. In: Ciba Foundation Symposium, 1996, 197, pp 300-311. Wiley.

29 Raper AB: Sickling in relation to morbidity from malaria and other diseases. Br Med J 1956, 1: 965-966. 
30 Bertranpetit J, Calafell F: Genetic and geographical variability in cystic fibrosis: evolutionary considerations. In: Ciba Foundation Symposium, 1996, 197, pp 97-114. Wiley.

31 Hill AV, Allsopp CE, Kwiatkowski D et al: Common west African HLA antigens are associated with protection from severe malaria. Nature 1991; 352: 595-600.

32 Ezekowitz RA: Genetic heterogeneity of mannose-binding proteins: the Jekyll and Hyde of innate immunity? Am J Hum Genet 1998; 62: 6-9.
33 Williams TN, Maitland K, Bennett S et al: High incidence of malaria in alpha-thalassaemic children. Nature 1996; 383: 522-525.

34 Pasvol G: Malaria and resistance genes: they work in wondrous ways. Lancet 1996; 348: 1532-1534.

35 Norris CF, Surrey S, Bunin GR, Schwartz E, Buchanan GR, McKenzie SE: Relationship between Fc receptor IIA polymorphism and infection in children with sickle cell disease. J Pediatr 1996; 128: 813-819. 